\title{
SOME PECULIARITIES OF ONTOGENESIS OF Orobanche cumana Wallr., PARASITIZING ON SUNFLOWER IN ROSTOV REGION OF RUSSIAN FEDERATION
}

Antonova, T.S. , Araslanova, N.M., Strelnikov, E.A., Ramazanova, S.A., Guchetl, S.Z., Tchelustnikova, T.A.

All Russia Research Institute of Oil Crops by the name of V.S. Pustovoit (VNIIMK), Laboratory of immunity and electrophoresis, 17 Filatova str., Krasnodar, 350038, Russia

Received: November 15, 2011 Accepted: December 10, 2011

SUMMARY

In the tubercle of $O$. cumana of high-virulent populations from Rostov region of Russian Federation some changes were found, which helped to improve the seed productivity and to decrease the development period of fruiting shoots. The maintenance of high level of seed productivity can be realized by setting multiple meristematic zones in a tubercle and simultaneous development of several adventive shoots from them. The maintenance of viability of tubercle and the formation of new shoot apexes after the seed ripening on one or several stems, grown out of it and finished in the vegetation period, also go in the favour of the improvement of seed productivity. The development of the apexes of tubercle rudimentary roots into adventive shoots was observed in this paper.

The polymorphism of inflorescence in the quantity of the setting flowers and their distribution along the stem and even below the soil level was observed. The flowering ability of flowers, hidden in the soil, and the seed formation in them, was defined. All that leads to the improvement of seed productivity of individual plant. On the whole, the described peculiarities of the development of $O$. cumana show that there is an accumulation of traits, which goes in the favour of the high potential of reproductive function in parasite's ontogenesis.

Key words: Helianthus, broomrape, tubercle, adventive shoots, inflorescence, reproductive function

* Corresponding author: Phone: +(861)275-86-53, Mobile: 89181888161 Fax: + (861)254-27-80, e-mail: antonova-ts@mail.ru 


\section{INTRODUCTION}

In Russia the broomrape (Orobanche cumana Wallr.) has a centenary history of parasitism on sunflower. During this period the harmful obligate parasite, which refers to higher floral plants, had exposed the sunflower to danger of disappearance. Its cultivation became unprofitable because of the strong affection of plants done by broomrape. The joined evolution of the parasite and the host had led to appearance of new races of parasite, capable to overcome the immunity of resistant varieties and hybrids.

The latest epiphytotic situation occurred in USSR at the beginning of 70's, when the biotype of broomrape appeared for the first time in Moldavia, called the Moldavian race, and began to affect the varieties, which were previously resistant, and had propagated in all regions of sunflower cultivation. However, the successful development and cultivation of varieties and hybrids, resistant to that race, lead to destruction of parasite's main seed stocks in fields, as they germinated in the presence of the roots of sunflower of both susceptible and resistant genotypes.

Since the middle of 80's until the end of 90's, the problem of broomrape on sunflower in Russia did not arise. It was even difficult to find and collect the necessary quantity of the seeds of that plant-parasite to test the resistance of the breeding material to it. Nevertheless, it took several years in the southern regions of the Russian Federation, especially in Rostov region, for all native assortment, as well as the hybrids of foreign breeding, to get strongly affected by the broomrape. That indicated the forthcoming fourth wave of countrywide epiphytotic effect of broomrape on sunflower in Russian Federation.

After a long pause of several decades the descriptive characteristics of morphologic traits and functional characters of $O$. cumana plants, parasitizing on sunflower in southern regions of Russian Federation, need to obtain more specific information.

The purpose of our research is to describe several peculiarities of $O$. cumana ontogenesis, found out in some individuals of the most virulent populations in Rostov region.

\section{MATERIALS AND METHODS}

The sunflower sowings were inspected in Belokalitvinskiy, Egorlikskiy, Konstantinovskiy and Tatsinskiy areas of Rostov region, where the most virulent biotypes of $O$. cumana had propagated. The collection of broomrape plants, with differences in morphology, was gathered. The parasite's seeds were collected and used for the creation of the infectious background in open ground, organized in central experimental base of VNIIMK. On this plot the observation of the development of parasite's plants were carried between 2009 and 2011, during the whole vegetation period of sunflower, followed by digging out of the plant-host and para- 

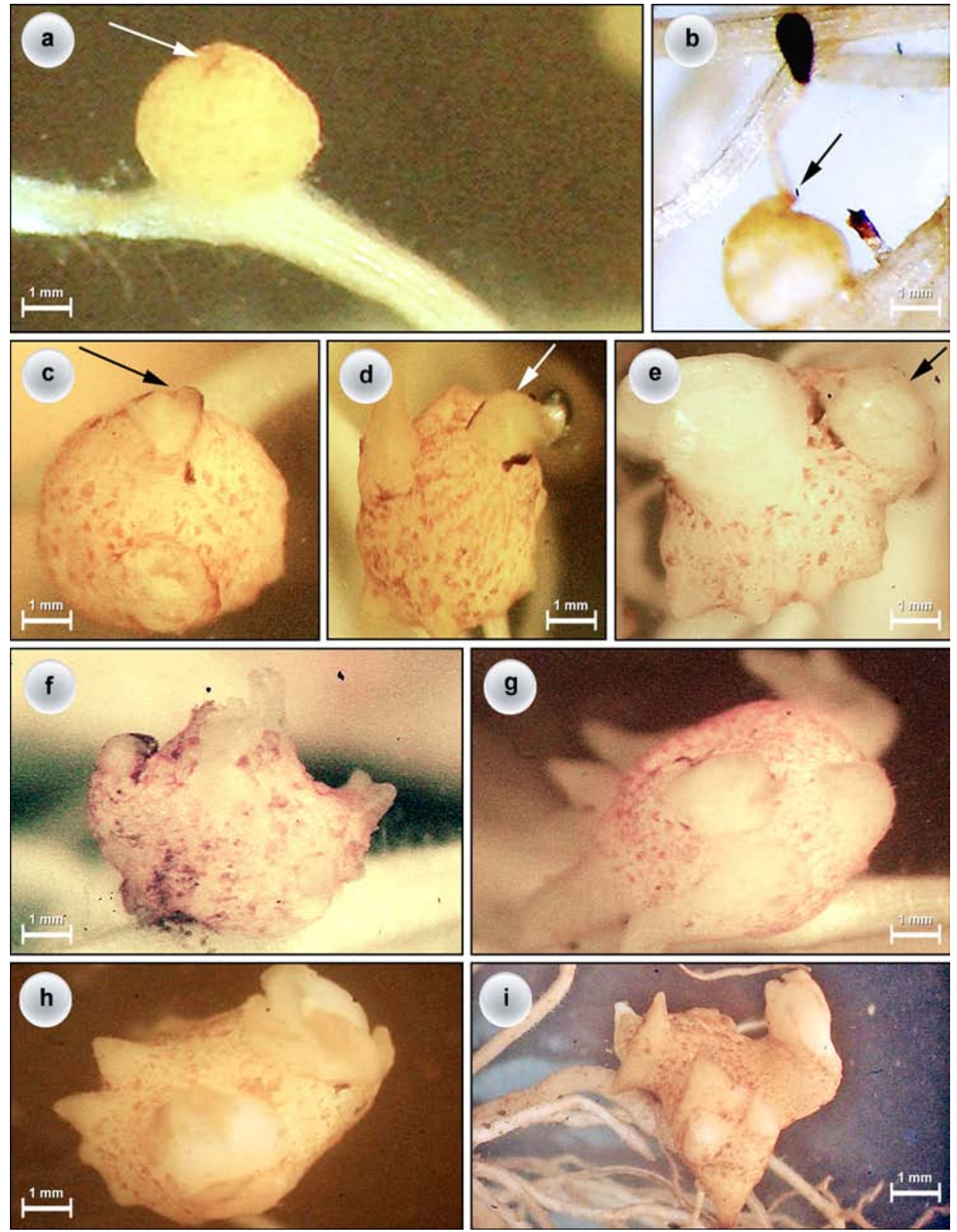

Figure 1: Two types of shoot apex formation in tubercle of O. cumana:

$\boldsymbol{a}$ - endogenous, $\boldsymbol{b}$ - exogenous.

$\boldsymbol{c}, \boldsymbol{d}, \boldsymbol{e}:$ Simultaneous development of two apexes: endogenous and exogenous (arrows) in tubercle of $O$. cumana.

$\boldsymbol{f}, \boldsymbol{g}, \boldsymbol{h}, \boldsymbol{i}:$ Plural apexes of adventive shoots developing from one tubercle of $O$. cumana. 


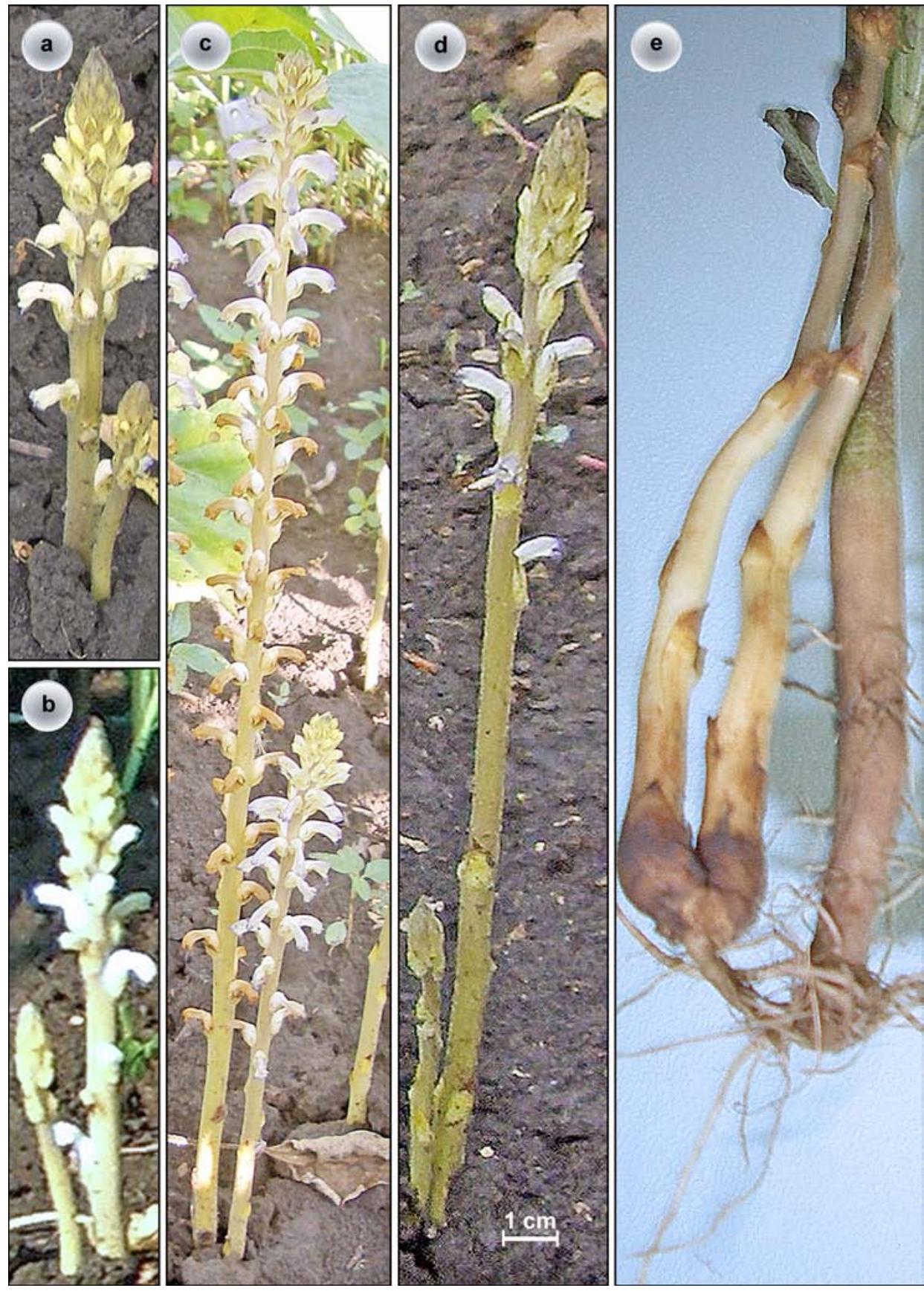

Figure 2: $\boldsymbol{a}, \boldsymbol{b}, \boldsymbol{c}, \boldsymbol{d}$ : Incomplete domination of one apex over another; $\boldsymbol{e}$-simultaneous development of two apexes equal in rights from one tubercle (arrow) of O. cumana. 
site and washing the roots. Early phases of broomrape plants development (tubercle formation and etc.) on the roots of sunflower were observed with the stereoscopic microscope. For that purpose, sunflower plants were grown and infested in greenhouse conditions according to the method of Panchenko (1975). The roots of 25-day old plants were washed with water, and the initial stages of the tubercle development were observed using microscope.

\section{RESULTS AND DISCUSSION}

In the studied populations of $O$. cumana from Rostov region, the species with the setting of multiple endogenous meristematic zones in tubercle and the formation of the apexes of adventives shoots from them are found fairly often (Figures 1f, $\mathrm{g}, \mathrm{h}, \mathrm{i})$. The frequency of occurrence of the forms with incomplete dominance of one stem is high (Figures 2a, b, c, d; Figures 3a, b), which happens when there is not only one stem growing out of tubercle, but 2 or more. Meanwhile, there are the forms found with strongly pronounced retardation of the growth of second shoot, and with simultaneous equality in the growth of both shoots (Figures 1c, d, e; Figure 2d).

The cultivar O. cumana has two known types of shoots development. The first one is an endogenous way of setting meristematic zones in tubercle (Figure 1a). This way of development is considered to be the main result of the evolution of parasitism in the family of Orobanchaceae. The major part of O. cumana shoots have the second type - an exogenous way of the stem development when the epicotylar zone of the reduced embryo, after the termination of its haustorial function in endosperm, does not die, but develop into the apex of the stem (Figure 1b). An individual stem grows out of it in the future. Exogenous formation of the stem apex results from adaptation to parasitism on annual (mostly, cultivated) plants-hosts, requiring a significant decrease of development period of the fruiting shoots (Teryokhin, Anisimova, 1978). Our data shows the high frequency of simultaneous development of shoots in studied populations of broomrape, which develop in various ways. The removal of the dominance of one shoot and the setting of multiple meristematic zones in tubercle contribute to it.

We have already shown (Antonova et al., 2009, 2010) the ability of O. cumana from the studied populations to form multiple adventive shoots (Figures 3a, b). However, it is known, that $O$. cumana parasitizing on sunflower in Europe, is characterized by a very small potential for reproduction of the shoots from tubercle tissues (Terekhin, Chubarov, 1996). As the authors noticed, the possible vegetative reproduction of this species on sunflower is limited by the formation of 1-3 shoots from one tubercle. The tubercle, meanwhile, transforms into the base of the major stem or some stems with corolla of rudimentary roots. On the whole, O. cumana tends to have one-stem form, with full dominance of one shoot. 


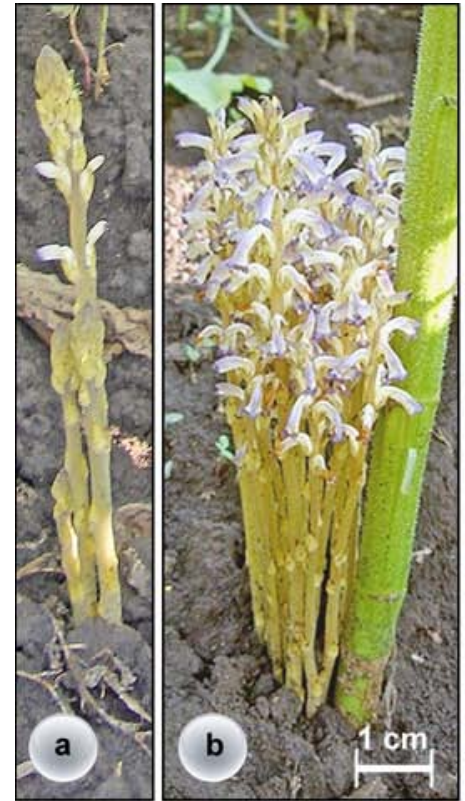

Figure 3: a, b: Plural adventive shoots of O. cumana.
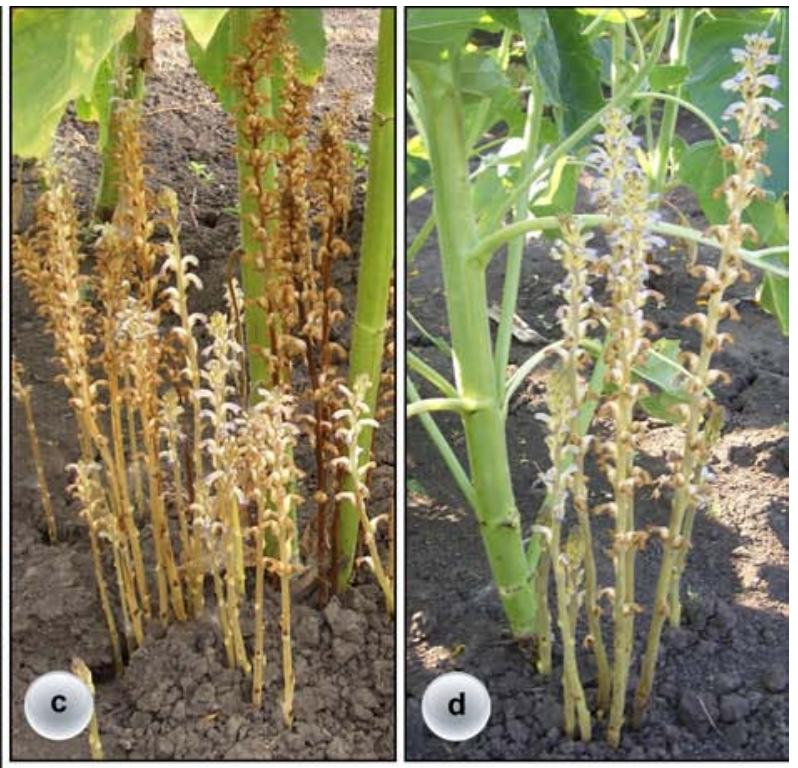

Figure 4: a, b: Typical shoots of O. cumana, having a friable inflorescence with widely placed flowers. The bottom part of a stem is without flowers.
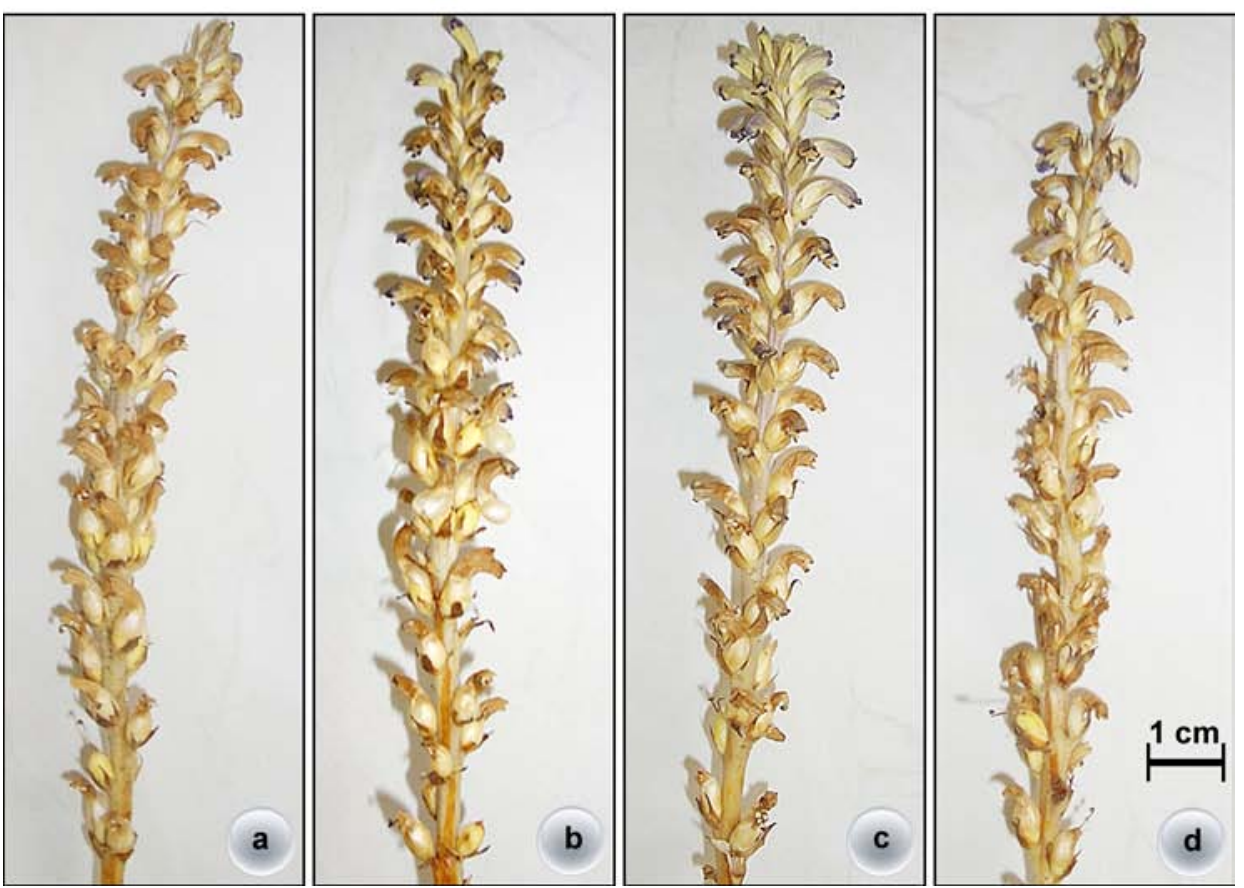

Figure 5: a, b, c, d: The inflorescences of O. cumana with close located flowers. 
The presence in O. cumana of the transitive forms of frequent occurrence with incomplete dominance of one shoot over another, is estimated as an evidence of the gradual evolutionary progress in $O$. cumana from full dominance of one stem to equal development of 2 or more stems simultaneously. In that we see one of the ways of improvement of the reproductive function of this parasite plant in the course of its evolution on sunflower.

We found out that the tubercle of $O$. cumana is able to form new shoots after the end of vegetation of one or more stems, grown out of it, and after spilling out of the ripen seeds (Figure 7). That curious phenomenon indicates, that the tubercle, besides its storing function, provide the support to the seed reproduction jointly with the vegetation period of the roots of the host. This fact can indicate, that the tubercle of $O$. cumana in the past was a perennial structure, and proves, that its ancestors parasitized on perennial species of plants.

Vegetative reproduction of O. cumana on sunflower in European countries - is a reduced form of perennial haustorial root type (Teryokhin, Chubarov, 1996). This type is characterized by rudimentary roots of tubercle, which penetrate in sunflower roots (Figures 9a, b), as soon as they are in contact with them, forming second haustorium. In the place of penetration a new tubercle is formed, from which the new shoot develops.

We have found out that the apexes of rudimentary roots of O. cumana can develop directly into adventive shoots omitting the stages of second penetration into sunflower root, development of new haustorium and tubercle (Figures 9d, e, f, g). This fact indicates a considerable reduction of the development period of additional fruiting shoots in parasite's ontogenesis. Finally, it indicates the accelerated additional seed reproduction from 1 broomrape individual, and, in general, the increase of the reproductive function's potential. As far as we know, for O. cumana on sunflower such a phenomenon hadn't been described yet in literature. It was described by Teryokhin and Chubarov (1996) for O. cernua Loefl., parasitizing on tobacco plants in India.

It is known, that O. cumana is a polyphage species and it has strong discrepancies in diverse morphological traits in the course of development on different species of plant-hosts (Kabulov, 1961). Clearly pronounced lability of morphological traits of polyphage species reflects their ability to develop on new, often systematically diverse species of plants-hosts (Teryokhin, Ivanova, 1965). Our researches had shown, that at the present time, a diversification of morphological traits of this species can be observed even on the one and the same host - sunflower. Thus, the studied populations of $O$. cumana have an expressive polymorphism of inflorescences. In "USSR Flora" it was mentioned, that the spike-like inflorescence of $O$. cumana on sunflower is usually friable with widely disposed lower flowers, and is equal to other part of the stem or is longer that it (Novopokrovskiy, Tsvelev, 1958). We observed the inflorescences both with widely (Figures $4 a$, b) and densely disposed flowers (Figures 5c, d, e, f). However, such diversity often occurred on one 


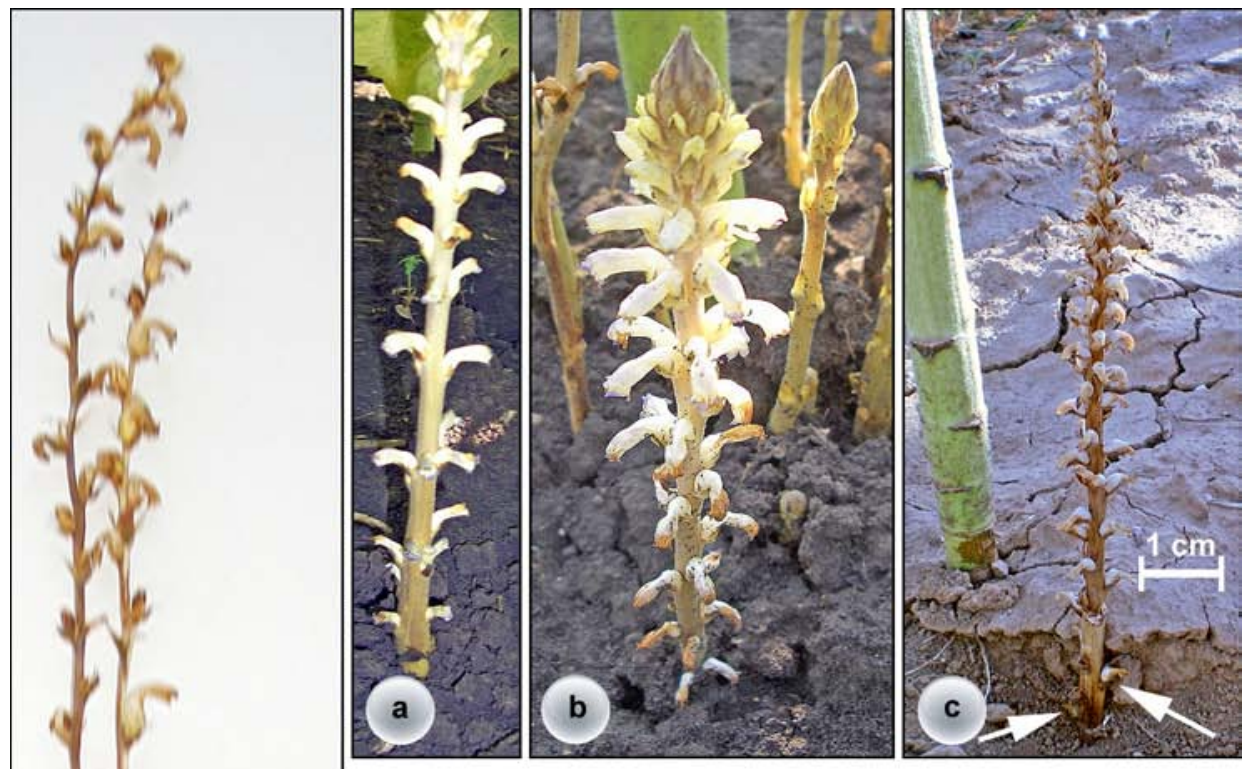

Figure 6: The inflorescences of O. cumana with flowers, settling down on all stem:

$\boldsymbol{a}, \boldsymbol{b}$ - on all overground part;

c-flowers (white arrows) are below soil level.

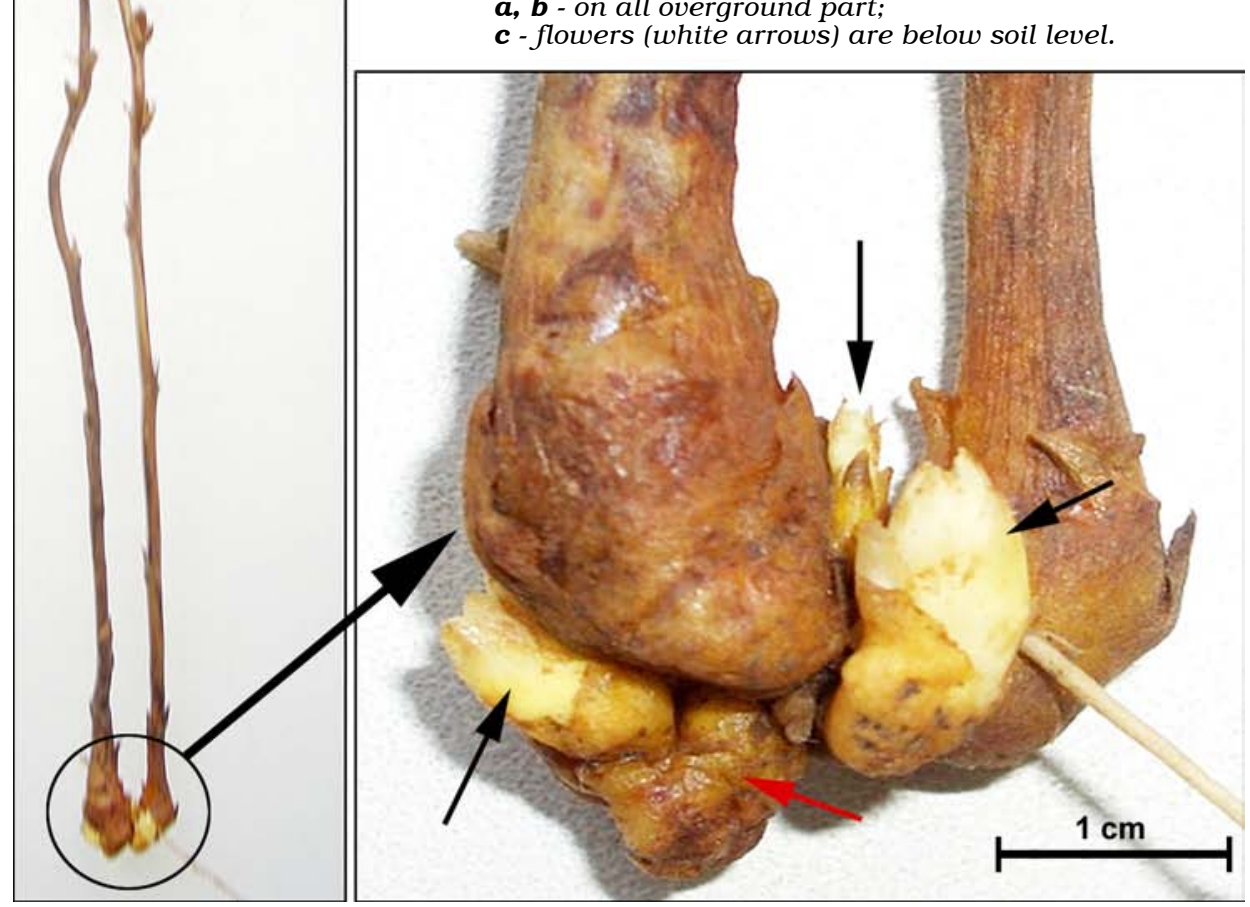

Figure 7: The development of new adventive shoots (black arrows) of O. cumana from tubercle (red arrow) after maturing of seeds on two other shoots which have grown from it and finished their vegetation. 

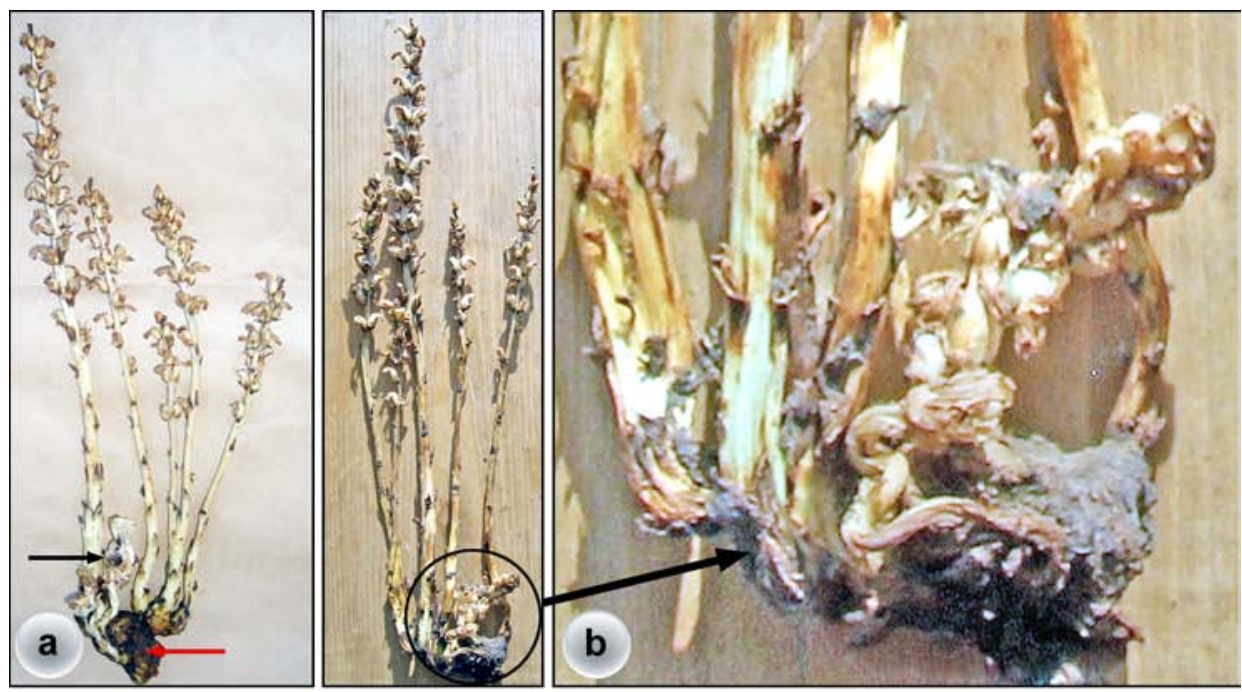

Figure 8: a, b: Plural adventive shoots of $O$. cumana from one tubercle (red arrow):

$\boldsymbol{a}$ - two weakest shoots (black arrow) have blossomed under the ground (black arrow); $\boldsymbol{b}$ - the weakest inflorescence has finished flowering, being hidden in soil and having generated seeds.
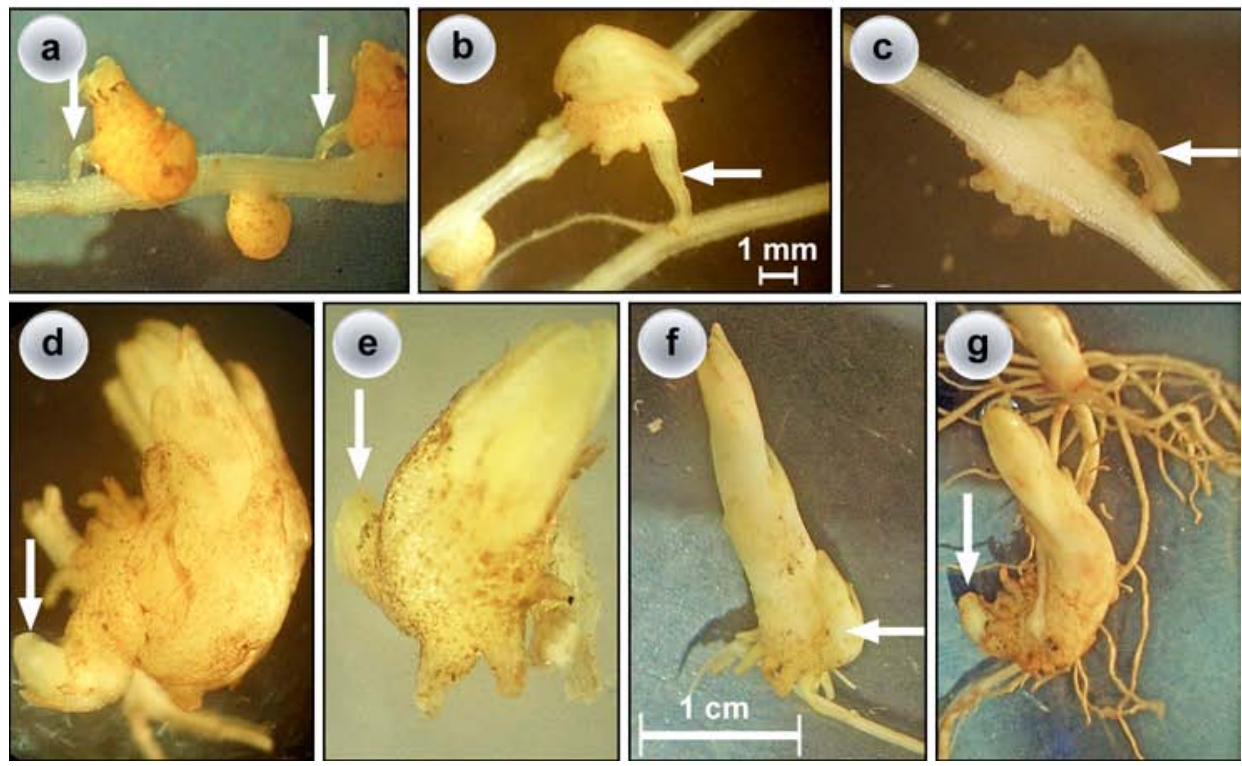

Figure 9: a, b, c: The usual function of rudimentary roots (arrows) of O. cumana tubercle. They come into contact to sunflower roots, penetrate into them, forming haustoria and the new tubercles.

$\boldsymbol{d}, \boldsymbol{e}, \boldsymbol{f}, \boldsymbol{g}:$ The apex of a rudimentary root of $O$. cumana tubercle develops directly in adventive shoot (arrows), passing stages of penetration into a root of sunflower, the haustorium development and formation of a new tubercle. 
and the same plant-host. Moreover, there was found out a phenomenon of frequent occurrence, which wasn't described yet, when the flowers are located on the whole stem, and even below the soil level (Figures 6a, b, c), though generally, in norm, the lower one third of the stem is deprived of them (Figures $4 \mathrm{a}, \mathrm{b}$ ). Flowers, located on the part of the stem which is covered by the soil, are capable of flowering and seed formation (Figures 8a, b). All that also indicates an evolutionary progress in improvement of the seed productivity in ontogenesis of that plant-parasite. It's quite natural, that in the situation of the constant extermination, the survival potential of the biotypes of the parasite, which succeed to make more numerous progeny in short period of time, will be higher, as they have a higher potential of reproductive function.

\section{CONCLUSION}

Thus, the changes in the tubercle of $O$. cumana can be observed, which help to improve the seed productivity and to decrease the development period of fruiting shoots. The maintenance of high level of seed productivity can be realized by setting multiple meristematic zones in tubercle and simultaneous development of several adventives shoots from them. The maintenance of viability of tubercle and the formation of new shoot apexes after the seed ripening on one or several stems, grown out of it and finished vegetation period, also go in the favour of the improvement of seed productivity. This process of the formation of new stems can be continued during all vegetation period of the plant-host. The development of the apexes of tubercle rudimentary roots into adventive shoots can also lead to the increase in the formation of the fruiting shoots.

The polymorphism of inflorescence in the quantity of the setting flowers and their distribution along the stem and even below the soil level was observed. The flowering ability of flowers, hidden in the soil, and the seed formation in them, was defined. All that leads to the improvement of seed productivity of individual plant. On the whole, the described peculiarities of the development of O.cumana show that there is an accumulation of traits, which favour the high potential of reproductive function in parasite's ontogenesis.

\section{REFERENCES}

Antonova, T.S., Araslanova, N.M., Ramazanova, S.A., Guchetl, S.Z., Tchelyustnikova, T.A., 2010a. Morphotypes of broomrape parasitizing on sunflower in Rostov region. Oil Crops, Scientific and Technical Bulletin of VNIIMK, Issue 1(142-143): 38-46. (In Russian)

Antonova, T.S., Araslanova, N.M., Ramazanova, S.A., Guchetl, S.Z., Tchelyustnikova, T.A., $2010 b$. Reproductive function potential of broomrape parasitizing on sunflower in the Rostov region. In: Proceedings of the International Symposium "Sunflower Breeding on Resistance to Diseases" Krasnodar, Russia, June 23-24, 2010. Pp. 107-111. [Electronic resource] URL: http://www.vniimk.ru/site/res/symposium/International_Symposium_Sunflower_Breeding_On_Resistance_To_Diseases_Proceedings.pdf (Last date of the reference: $03 \cdot 1 \overline{0} \cdot 2011$ ). 
Novopokrovsky, I.V., Tsvelyov, N.N., 1958. Orobanchaceae family. Flora of the USSR, Vol. XXIII: 19-115. (In Russian)

Kabulov, D.T., 1961. Materials for the knowledge of broomrapes of Uzbekistan. Works of the Samarkand University 109: 92-117. (In Russian)

Panchenko, A.Y., 1975. Early diagnostics of resistance to broomrape in breeding and improving of sunflower seed-growing. The Bulletin of an Agricultural Science 2: 107-115. (In Russian)

Teryokhin, E.S., Anisimova, G.M., 1978. About some peculiarities development of Orobanche cumana Wallr. (Orobanchaceae). Bot. Journal 63(6): 797-803. (In Russian)

Teryokhin, E.S., Chubarov, S.I., 1996. Two modes of the vegetative propagation in Orobanche cernua (Orobanchaceae). Advances in parasitic plant research. $6^{\text {th }}$ International Parasitic Weed Symposium, Junta de Andalucía, Spain. Pp. 243-248.

Teryokhin, E.S., Ivanova, G.I., 1965. Towards the taxonomy of Orobanchaceae of the Caucasus. Bot. Journal 50(8): 1105-1112. (In Russian) 
